\title{
ENSINO E PESQUISA NA PUC-SP MARCAM 20 ANOS DE PRESENÇA/AUSÊNCIA DE PAULO FREIRE
}

Ana Maria Saul ${ }^{1}$

\begin{abstract}
Resumo
Paulo Freire foi professor da Pontifícia Universidade Católica de São Paulo (PUC-SP) pelo período de quase duas décadas, desde sua volta do exílio. Quando ele já não estava entre nós, em 1998, a reitoria da PUC-SP criou a Cátedra Paulo Freire, um espaço acadêmico singular para o desenvolvimento de estudos e pesquisas sobre e a partir da obra de Paulo Freire. Transcorridos vinte anos de ausência do autor da Pedagogia do Oprimido, é possível afirmar que a sua ausência é presença no mundo, porque o seu pensamento é clássico e atual. Este artigo tem o objetivo de apresentar como a pedagogia freireana segue sendo estudada, pesquisada e reinventada na Cátedra Paulo Freire da PUC-SP. O destaque desse texto é demonstrar a possibilidade de materializar a relação "ensino-pesquisa", assim como foi compreendida por Paulo Freire, e como uma pesquisa de abrangência nacional analisa o legado e a reinvenção do pensamento desse autor que nos deixou "à moda de quem, saindo, fica."
\end{abstract}

Palavras-chave: Paulo Freire; Ensino-Pesquisa; Cátedra Paulo Freire

\section{PRIMEIRAS PALAVRAS}

Paulo Freire nos deixou "à moda de quem, saindo, fica". Essa expressão nomeia as últimas páginas do livro Educação na cidade (FREIRE, 1991), publicado logo depois que Freire ausentou-se da Secretaria Municipal de São Paulo, para escrever e para atender aos

\footnotetext{
${ }^{1}$ Doutora em Educação (Psicologia da Educação) pela Pontifícia Universidade Católica de São Paulo. É professora da PUC-SP desde 1970 e atualmente atua nos Programas de Pós-Graduação em Educação: Currículo e Educação: Formação de Formadores. Coordena a Cátedra Paulo Freire dessa instituição, onde desenvolve ensino e pesquisa. É coordenadora do Grupo de Pesquisa: O pensamento de Paulo Freire na educação brasileira. Endereço: Rua Ministro de Godói, 969, Perdizes, São Paulo, SP. CEP: 05015-901. E-mail: anasaul@ uol.com.br Revista Reflexão e Ação, Santa Cruz do Sul, v. 25, n. 2, p. 119-133, Maio./Ago. 2017. http://online.unisc.br/seer/index.php/reflex/index
} 
convites que lhe eram feitos como cidadão do mundo. Nesse Manifesto ${ }^{2}$, assim se expressa Freire (1991, p.43): "Não estou rigorosamente, saindo da Secretaria Municipal de Educação deixando a companhia de vocês. [...] Mesmo sem ser secretário continuarei na companhia de vocês, de outra forma. Vou ficar mais livre para assumir outro tipo de presença."

Ele entendia que poderia seguir contribuindo com a equipe que com ele trabalhou na Secretaria de Educação, responsável por implementar a proposta de política educacional por ele apresentada, no governo de Luiza Erundina de Sousa: "Não estou deixando a luta, mas mudando, simplesmente de frente. A briga continua a mesma. Onde quer que esteja estarei me empenhando, como vocês, em favor da escola pública, popular e democrática" (FREIRE, 1991, p.144).

Hoje, transcorridos vinte anos de ausência do autor da Pedagogia do Oprimido, retomo a analogia expressa naquele manifesto para afirmar que a ausência de Paulo Freire é presença no mundo, porque o seu pensamento é clássico e atual.

O objetivo deste texto é apresentar como a pedagogia de Paulo Freire segue sendo estudada, pesquisada e reinventada na Cátedra Paulo Freire da Pontifícia Universidade Católica de São Paulo.

\section{PAULO FREIRE: UM PENSAMENTO CLÁSSICO E ATUAL}

Paulo Freire é reconhecido, internacionalmente, por sua luta intransigente contra as situações de opressão, por sua práxis em favor da democracia e justiça social e por sua inestimável contribuição nos campos da educação crítica, filosofia e política. Ao lado dessas marcas de sua trajetória, a biografia de Freire registra uma importante face de sua atuação, nem sempre conhecida, a de gestor público da cidade de São Paulo, tendo assumido a pasta da Educação, a convite da prefeita Luiza Erundina de Sousa, do Partido dos Trabalhadores, no ano de 1989 a 1992.

O crescente interesse em aprofundar o estudo sobre Paulo Freire, evidenciado em debates e trabalhos teóricopráticos realizados sobre e, a partir de suas propostas e práticas, em diferentes áreas do conhecimento, ao redor do mundo, demonstra a atualidade do pensamento desse autor, reconhecido como um dos maiores educadores do século XX. A reedição de suas obras, das quais Pedagogia do Oprimido se destaca, em dezenas de idiomas, confere ao

\footnotetext{
${ }^{2}$ Síntese da fala de despedida da Secretaria Municipal de Educação do Município de São Paulo, em maio de 1991.

Revista Reflexão e Ação, Santa Cruz do Sul, v. 25, n. 2, p. 119-133, Maio./Ago. 2017. http://online.unisc.br/seer/index.php/reflex/index
} 
conjunto de suas produções o caráter de uma obra universal, o que vem sendo admitido por reconhecidos autores da área da Educação, na literatura nacional e internacional.

A esse propósito, assim se manifesta António Nóvoa (1998, p. 185):

\begin{abstract}
A vida e a obra de Freire estão inscritas no imaginário pedagógico do século XX, constituindo uma referência obrigatória para várias gerações de educadores. [...] As propostas por ele lançadas foram sendo apropriadas por grupos distintos, que as relocalizaram em vários contextos sociais e políticos. [...] A partir de uma concepção educativa própria, que cruza a teoria social, o compromisso moral e a participação política, Paulo Freire é, ele próprio, um patrimônio incontornável da reflexão pedagógica atual. A sua obra funciona com uma espécie de consciência crítica, que nos põe em guarda contra a despolitização do pensamento educativo e da reflexão pedagógica.
\end{abstract}

O pensamento de Paulo Freire ultrapassa as fronteiras da área da educação, stricto sensu e se alonga para diferentes campos do conhecimento. Nas últimas duas décadas e no presente, observa-se considerável ampliação de trabalhos referenciados no legado freireano ${ }^{3}$. O portal da Coordenação de Aperfeiçoamento de Pessoal de Nível Superior (CAPES) ${ }^{4}$ registra 1843 produções, entre dissertações e teses, que incluem conceitos e pressupostos da obra de Freire, no período 1987 a 2012, em seus quadros teóricos.

O conjunto dessas evidências permite afirmar que Paulo Freire é um clássico e que o seu pensamento é novo e atual. A esse respeito, Cortella (2011, p. 10-11). assim escreve:

[...] É preciso não confundir novo com novidade. Novidade é aquilo que vem, é passageiro, se coloca por um tempo, mas tem um nível de volatilidade muito grande e depois se vai. Educação tem muita novidade, que é algo da moda, algo episódico. Muito diferente disso, é aquilo que na história humana é novo. A diferença entre novo e novidade é que o novo vem, se instala, muda e permanece. O novo permanece porque ele mantém vitalidade. A novidade passa logo. O pensamento de Paulo Freire é novo, a música de Mozart é nova, a obra de Platão é nova. [...] Por quê? Porque o seu trabalho não perdeu vitalidade, não perdeu a irrigação, não perdeu a conexão com a vida e com o sangue que a vida partilha e emana. Desse ponto de vista, o pensamento de Paulo Freire é absolutamente atual, no sentido de guardar a sua forma de ser novo.

E acrescenta: "Freire é um clássico porque o seu trabalho não perdeu vitalidade, não perdeu irrigação, conexão com a vida e com o sangue que a vida partilha e emana" (CORTELLA, 2011, p. 11).

\footnotetext{
${ }^{3} \mathrm{O}$ uso deliberado do adjetivo freireano e flexões, assumido nesse texto e em produções da Cátedra Paulo Freire da PUC-SP, é uma questão de preferência, pela compreensão de que a manutenção da grafia integral do sobrenome do autor destaca com mais vigor a procedência das produções: a matriz de pensamento de Paulo Freire. Em alguns redutos acadêmicos significativos seguiu-se, pois, o seguinte critério: à ortografia original do antropônimo, foi acrescentado o sufixo ano, resultando no adjetivo freireano.

${ }^{4}$ Órgão vinculado ao Ministério da Educação e Cultura (MEC), responsável pela avaliação da pós-graduação stricto sensu.
}

Revista Reflexão e Ação, Santa Cruz do Sul, v. 25, n. 2, p. 119-133, Maio./Ago. 2017. http://online.unisc.br/seer/index.php/reflex/index 
Schugurensky (2014), ao analisar a atualidade da perspectiva popular, radical e democrática da proposta de Freire, particularmente no presente contexto de reformas educacionais neoliberais e neoconservadoras assinala que, presentemente, há uma comunidade considerável de intelectuais e práticos interessada no exame crítico, na extensão criativa e na aplicação imaginativa das ideias de Freire.

\section{UM POUCO DA TRAJETÓRIA DE FREIRE}

Ao lado das marcas de sua trajetória como educador e filósofo, a biografia de Freire registra uma importante face de sua atuação, nem sempre conhecida, a de gestor público da cidade de São Paulo, tendo assumido a pasta da Educação, a convite de Luiza Erundina de Sousa, prefeita eleita no ano de 1989. Freire demonstra em sua prática de gestor público, o valor e a possibilidade de se fazer educação popular na escola.

Retomo um de seus escritos datado de 1993, Escola pública e Educação popular, no qual Paulo Freire sistematiza o seu pensamento com a intenção de responder afirmativamente à indagação: é possível fazer educação popular na escola pública?

Os argumentos de Freire (1993a, p.101-103) em suas próprias palavras, são apresentados a seguir:

[...] a educação popular cuja posta em prática, em termos amplos, profundos e radicais numa sociedade de classe, se constitui como um nadar contra a correnteza é exatamente a que, substantivamente democrática: - jamais separa do ensino dos conteúdos o desvelamento da realidade; - respeita os educandos, não importa qual seja sua posição de classe e, por isso mesmo, leva em consideração, seriamente, o seu saber de experiência feito, a partir do qual trabalha o conhecimento com rigor de aproximação aos objetos; - trabalha, incansavelmente, a boa qualidade do ensino [...] através de rigoroso trabalho docente e não com frouxidão assistencialista; - capacita suas professoras cientificamente à luz dos recentes achados em torno da aquisição da linguagem do ensino da escrita e da leitura; - [está atenta à necessária] formação científica e clareza política de que as educadoras e os educadores precisam para superar os desvios que, se não são experimentados pela maioria, se acham presentes em maioria significativa[...]; - em lugar de negar a importância da presença [...] da comunidade, dos movimentos populares na [instituição educacional] se aproxima dessas forças com as quais aprende para a elas poder ensinar também [...]; - supera os preconceitos de raça, de classe, de sexo e se radicaliza na defesa da substantividade democrática [...]; - não considera suficiente mudar apenas as relações entre [educadores] e educandos, amaciando essas relações, mas, ao -criticar e tentar ir além das tradições autoritárias da escola velha, critica também a natureza autoritária e exploradora do capitalismo. E ao realizar-se, assim, como prática eminentemente política, tão política quanto a que oculta, nem por isso transforma [a instituição] onde se processa, em sindicato. É que os conflitos sociais, o jogo de interesses, as contradições que se dão no corpo da sociedade se refletem necessariamente no espaço das [instituições educativas]. 
Os princípios da educação popular foram levados por Freire para a administração pública. Em sua carta dirigida aos educadores de São Paulo (SÃO PAULO, 1989), publicada no Diário Oficial do Município, logo após tomar posse como Secretário, Paulo Freire anunciava a construção de uma escola voltada para a formação social e crítica dos educandos, uma escola séria, na apropriação e recriação de conhecimentos e, ao mesmo tempo alegre, estimuladora da solidariedade e da curiosidade. A abertura da escola à comunidade, a construção do currículo, de forma participativa, autônoma e coletiva, o estímulo à gestão democrática da educação, o respeito ao saber do educando, e a indispensável formação dos educadores, foram marcos fundamentais que nortearam o seu quefazer na educação de São Paulo.

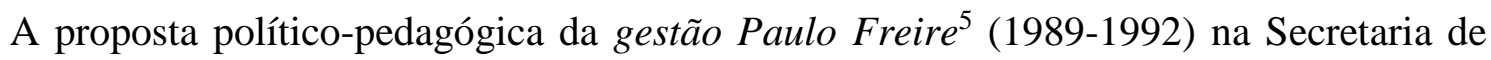
São Paulo tem inspirado redes públicas de ensino no Brasil que assumem os valores de uma educação crítico-emancipadora.

Nesse artigo cabe ressaltar a importante presença de Paulo Freire na Pontifícia Universidade Católica de São Paulo (PUC-SP), na qual assumiu a docência e a orientação de pesquisas no Programa de Pós-Graduação Educação: Currículo, durante quase duas décadas, depois de sua volta do exílio, (1980 a 1997).

Quando Freire já não estava entre nós, em 1998, a reitoria da PUC-SP aprovou a proposta de criação da Cátedra Paulo Freire, atribuindo a direção da mesma ao Programa de Pós-Graduação em Educação: Currículo.

A Cátedra é um espaço acadêmico singular para o desenvolvimento de estudos e pesquisas sobre e a partir da obra de Paulo Freire, focalizando as suas contribuições teóricas e práticas para a Educação e a sua potencialidade de fecundar novos pensamentos. Os cursos da Cátedra, oferecidos semestralmente, podem ser frequentados por alunos dos Programas de Pós-Graduação de diferentes áreas. Por eles já passaram mais de 1000 estudantes, desde o $2^{\circ}$ semestre de 1998. Os temas que são desenvolvidos nos diferentes semestres, aprofundam a política, a teoria e a prática da Pedagogia de Paulo Freire e pesquisam possibilidades de reinvenção do seu legado.

\section{ENSINO-PESQUISA NA CÁTEDRA PAULO FREIRE}

\footnotetext{
${ }^{5}$ Embora Paulo Freire tenha deixado a pasta da Educação, todo o período dessa gestão municipal (1989-1992) ficou conhecido como gestão Paulo Freire porque as propostas da política educacional desse Secretário foram mantidas pelo professor Mário Sergio Cortella que o sucedeu.
}

Revista Reflexão e Ação, Santa Cruz do Sul, v. 25, n. 2, p. 119-133, Maio./Ago. 2017.

http://online.unisc.br/seer/index.php/reflex/index 
Ensino e pesquisa tem sido, por vezes, discutidos na academia como componentes das funções da universidade, ao lado da extensão. Portanto, embora não seja uma preocupação nova, a associação do ensino à pesquisa vem sendo tratada, como diria Paulo Freire, com a presença do conectivo "e". Isto significa que ensino e pesquisa convivem, de forma paralela ou sobreposta.

Não raras vezes encontra-se na fala de professores, e mesmo na literatura, diferentes argumentos para justificar a necessidade da pesquisa, como contribuição para o ensino. Dentre as razões que justificam a associação ensino e pesquisa, algumas são consideradas de mérito e outras, burocráticas.

No contexto de quadros de referência que consideram que a pesquisa pode "ilustrar" o que o professor apresenta na aula ou ser uma forma de prática da teoria, encontram-se expressões tais como "é importante que os alunos pesquisem para corroborar o que estamos ensinando"; "somente pesquisando os alunos aprendem a utilizar os métodos de pesquisa". E ainda, "ao fazer pesquisa, os alunos podem aplicar a teoria que estamos ensinando".

Dentre os argumentos de ordem burocrática são encontradas referências como "a pesquisa é uma exigência do contrato do professor universitário", e também, falas como essa: “o professor da pós-graduação não pode deixar de pesquisar, afinal, esta é uma exigência dos critérios da avaliação da Pós-Graduação".

A relação ensino - pesquisa implica, portanto, diferentes compreensões e práticas.

A compreensão de Paulo Freire a respeito da relação ensino - pesquisa, assumida na Cátedra Paulo Freire, apresenta uma justificativa coerente com o seu entendimento de "ciclo gnosiológico". Significa dizer que o ensino, porque enseja produção de conhecimento, tem uma exigência metódica, rigorosa, que transita da ingenuidade para a "curiosidade epistemológica".

Em Pedagogia da Autonomia, Freire (1996, p. 29). explicita o seu entendimento sobre ensino-pesquisa:

Não há ensino sem pesquisa e pesquisa sem ensino. [...] No meu entender, o que há de pesquisador no professor não é uma qualidade ou uma forma de ser ou de atuar que se acrescente à de ensinar. Faz parte da natureza da prática docente a indagação, a busca, a pesquisa. Esses que - fazeres se encontram um no corpo do outro. Enquanto ensino, continuo buscando, reprocurando. Ensino porque busco, porque indaguei, porque indago e me indago. Pesquiso para constatar, constatando, intervenho, intervindo educo e me educo. Pesquiso para conhecer o que ainda não conheço e comunicar ou anunciar a novidade. [...] O de que se precisa é que, em sua formação permanente, o professor se perceba e se assuma, porque professor, como pesquisador. 
E acrescenta, no livro Política e Educação: “[...] Não se faz pesquisa, não se faz docência como não se faz extensão como se fossem práticas neutras. Preciso saber a favor de que e de quem, portanto contra que e contra quem pesquiso, ensino ou me envolvo em atividades mais além dos muros da Universidade" (FREIRE, 1993a, p.113).

É a sala de aula, compreendida como um espaço-tempo no qual educandos e educadores se relacionam, mediatizados por objetos de conhecimento o lócus privilegiado no qual se constrói e se desenvolve a relação ensino-pesquisa. Esse é um contexto de múltiplas possibilidades.

Escreve Paulo Freire (1981, p.14): “[...] nenhuma prática educativa se dá no ar, mas num contexto concreto, histórico, social, cultural, econômico, político, não necessariamente idêntico a outro contexto."

Para o autor contexto é: “[...] o mundo dos fatos, o mundo da vida, o mundo no qual os eventos estão muito vivos, o mundo das lutas, o mundo da discriminação, o da crise econômica [e também o mundo da escola]" (FREIRE; SHOR, 1987, p.164).

Estar na sala de aula é compartilhar um espaço-tempo com sujeitos que vivem e se relacionam em diferentes contextos e trazem consigo experiências diversas. Nesse campo, o da sala de aula, entrelaçam-se, pois, diferentes contextos que carregam dimensões históricas, políticas, sociais, cognitivas, linguísticas, afetivas e outras.

A figura 1, a seguir, ilustra esse entrelaçamento de contextos que se dá na sala de aula. Fig. 1- A sala de aula: um entrelaçamento de contextos

\section{A sala de aula: um entrelaçamento de contextos.}

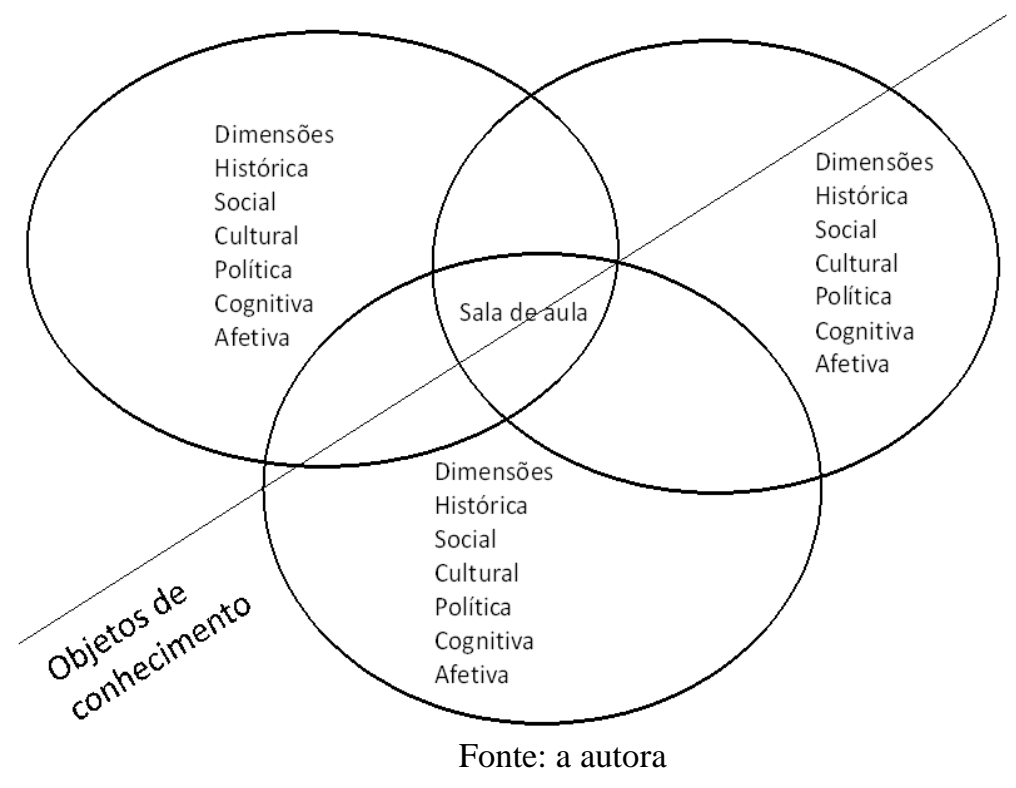

Revista Reflexão e Ação, Santa Cruz do Sul, v. 25, n. 2, p. 119-133, Maio./Ago. 2017. http://online.unisc.br/seer/index.php/reflex/index 
É nesse lócus de ensino-aprendizagem, mediado por objetos de conhecimento, que as dinâmicas da realidade são problematizadas e analisadas, norteadas por intencionalidades e recortes temáticos.

Em diferentes partes de sua obra, Freire se refere ao contexto, porém, é em Professora sim, tia não - cartas a quem ousa ensinar, que ele dedica 15 páginas da carta número 9, para tratar especificamente do conceito de contexto, sendo que esse capítulo do livro foi assim nomeado: Contexto concreto - contexto teórico. Nesse capítulo ele destaca a dialeticidade entre prática e teoria apontando que essa deve ser plenamente vivida nos contextos teóricos de formação.

Assim se manifesta o autor:

Como contexto prático-teórico a escola não pode prescindir de conhecimentos em torno do que se passa no contexto concreto, de seus alunos e das famílias deles. [...] Isso se refere, tanto às situações-limite como em relação às condições, modos e conteúdos de aprendizagem que ocorrem fora da escola e que constituem um saber de experiência feito. (FREIRE, 1993b, p.106).

A leitura do contexto é condição para que o professor possa criar ambientes/situações que estimulem a curiosidade, a investigação e o desenvolvimento da criatividade dos estudantes, possibilitando que eles atribuam sentido ao conhecimento que se constrói na sala de aula.

O trabalho que vem se construindo no espaço da Cátedra tem o compromisso de não dicotomizar ensino e pesquisa, teoria e prática. Nessa perspectiva, dialoga-se com a prática em dois contextos que interagem e se interpenetram, o do ensino e o da pesquisa.

A proposta de ensino, referenciada em pressupostos da dialogicidade freireana, assume o papel político - epistemológico de tomar a realidade concreta da educação, a partir da leitura dos educandos, como objeto de ensino e investigação, na formação crítica do educadorpesquisador.

Como nos lembra Freire na Pedagogia da Autonomia ${ }^{6}$, conceber a prática de ensino como um processo de permanente investigação significa assumir o posicionamento epistemológico em que o educando é o sujeito de seu conhecimento, estando sua aprendizagem associada a um processo constante de pesquisa sobre sua realidade. Em outras palavras, significa não distanciar a prática educativa do exercício da curiosidade epistemológica dos educandos.

De acordo com Freire (1981, p.145): “[...] o conhecimento da realidade é indispensável

\footnotetext{
${ }^{6}$ Consultar Paulo FREIRE (1996).

Revista Reflexão e Ação, Santa Cruz do Sul, v. 25, n. 2, p. 119-133, Maio./Ago. 2017.

http://online.unisc.br/seer/index.php/reflex/index
} 
ao desenvolvimento da consciência de si e este ao aumento daquele conhecimento. Mas o ato de conhecer que, se autêntico, demanda sempre o desvelamento de seu objeto, não se dá na dicotomia entre objetividade e subjetividade, ação e reflexão, prática e teoria.”

Em linha com esse posicionamento epistemológico, a pesquisa visa a apreender a prática educacional a partir dos interesses de investigação e de vivências pedagógicas dos educandos como realidade concreta que se dá, de acordo com Freire (1991), na relação dialética entre objetividade e subjetividade.

Nesse contexto de ensino-pesquisa, a prática é trazida para a sala de aula por meio das representações da realidade e pelo saber de experiência feito dos educandos-pesquisadores. Nos momentos presencias coletivos das aulas, o ponto de partida é o relato dos participantes, as suas "curiosidades ingênuas ou epistemológicas". Esse trabalho inicial consiste em identificar os diferentes interesses de investigação de mestrandos e doutorandos, bem como suas práticas de pesquisa e ou de docência, para problematizar os limites de suas concepções e os seus temas de investigação. São delineados, a seguir, múltiplos itinerários para a compreensão crítica da realidade que está sendo/será investigada, com a mediação feita, centralmente, pela obra de Paulo Freire. Ao trilhar diferentes percursos de leitura, orientados em função de seus problemas de pesquisa, o educando-pesquisador torna-se o sujeito de seu processo de aprendizagem e faz uma constante reflexão sobre seu objeto de pesquisa, o que lhe permite novos olhares sobre a realidade e um retorno crítico ao campo de investigação.

Freire destaca por vezes, em sua obra, a importância de valorizar o conhecimento que o educando traz, partindo do mesmo, para superá-lo.

Em À sombra dessa mangueira escreve:

A priorização da "relação dialógica" no ensino que permite o respeito à cultura do aluno, a valorização do conhecimento que o educando traz, enfim, um trabalho a partir da visão do mundo do educando é sem dúvida um dos eixos fundamentais sobre os quais deve se apoiar a prática pedagógica de professoras e professores. (FREIRE, 1995, p. 82).

No texto que relata a experiência docente de um semestre na Cátedra, assumindo-se o modelo de "docência compartilhada", os autores (SAUL; SAUL, 2016) sintetizam as avaliações que os alunos fizeram do trabalho da Cátedra, nesse semestre. Solicitou-se que os alunos fizessem uma reflexão crítica do semestre, analisando suas expectativas iniciais, o percurso trilhado e os resultados.

A contribuição das aulas para as dissertações e teses dos alunos foi fortemente apontada, tanto para a fundamentação teórica como para a metodologia da investigação que 
realizam. O trabalho realizado com "tramas conceituais freireanas", uma criação da Cátedra Paulo Freire, desde 2001, para relacionar conceitos da obra de Freire, chamou muito a atenção do grupo-classe e, em virtude desse fato, várias tramas conceituais foram construídas, de acordo com os interesses/necessidades de pesquisa desse grupo de estudantes. Outros registros avaliativos dos alunos demonstraram a contribuição do curso para as práticas de educadores, quer na docência, quer na gestão de escolas ou em outras instâncias da educação. As produções escritas foram discutidas nas aulas, como mais um momento da trajetória de formação de alunos e professores.

Escrevem Ana Maria Saul e Alexandre Saul (2016, p.81):

As análises e [discussões dos registros dos alunos] constituíram momentos valiosos de avaliação formativa, conquanto que geraram novas produções de conhecimento e indicações importantes para os próximos semestres de trabalho da Cátedra Paulo Freire. Ao mesmo tempo, foram momentos prazerosos porque o grupo desenvolveu relações de respeito e confiança, que permitiram uma convivialidade amorosa e solidária.

E acrescentaram, no tocante à avaliação do curso:

[...] A experiência docente, pode consolidar uma proposta de docência compartilhada com dois professores que trabalharam em uma perspectiva colaborativa, nos momentos de planejamento e em cada aula, semanalmente. Ao analisar, com os alunos, a prática de docência compartilhada dos professores que conduziram o trabalho da Cátedra nesse semestre, foi possível percorrer muitos dos 27 saberes docentes apresentados por Paulo Freire em Pedagogia da autonomia, saberes necessários à prática docente. Constatou-se que o diálogo, o respeito, a autonomia partilhada, a interdisciplinaridade, a humildade, os saberes de experiência feito, dentre outros, são saberes que foram se tramando, necessariamente, nessa construção dessa proposta de docência construída e experienciada na Cátedra Paulo Freire da PUC-SP, nesse semestre (SAUL; SAUL, 2016, p.82).

A docência, na Cátedra Paulo Freire, tem atestado a possibilidade e o valor de se trabalhar com princípios da pedagogia freireana no ensino superior e, em especial, na pósgraduação. Assumindo o compromisso ético-político de desenvolver a docência a partir da problemática de pesquisa e dos interesses/experiência dos educandos, como ponto de partida do processo crítico de construção de conhecimentos, a Cátedra propôs-se a contribuir para a formação de pesquisadores em uma vertente contra hegemônica, porque defende uma

\footnotetext{
${ }^{7}$ [...] A Cátedra Paulo Freire vem utilizando a prática de construção de tramas conceituais como forma de trabalhar com conceitos apresentados na obra de Paulo Freire. O que faz com que as tramas sejam possíveis é o caráter relacional do pensamento desse autor. [...] Os conceitos implicam-se mutuamente em diversas direções possíveis. Embora plural, a construção da trama conceitual freireana requer atenção ao fato de que as articulações propostas respeitem a lógica interna da obra de Freire. A trama pode integrar diferentes conceitos abarcados pela obra, tendo em vista explicitar a leitura que o autor dessa construção faz da relação entre os conceitos (SAUL, A. M; SAUL, A, 2013, p.107-108).
}

Revista Reflexão e Ação, Santa Cruz do Sul, v. 25, n. 2, p. 119-133, Maio./Ago. 2017.

http://online.unisc.br/seer/index.php/reflex/index 
proposta que se opõe a processos formativos prescritivos, reprodutivistas e conteudistas de educação.

\section{UM ALONGAMENTO DA PESQUISA: A BUSCA DA MATERIALIZAÇÃO DA PEDAGOGIA DE PAULO FREIRE EM DIFERENTES TERRITÓRIOS}

A revista científica e-Curriculum publicou um dossiê em janeiro de 2016, com artigos que sintetizam as duas primeiras edições da pesquisa que investiga a presença e reinvenção da pedagogia de Paulo Freire em diferentes espaços da realidade brasileira. A professora Ana Maria Saul (2016), coordenadora dessa pesquisa e da Cátedra Paulo Freire da PUC-SP, explica que essa pesquisa, gestada na Cátedra, se desenvolve, em âmbito nacional, desde o ano de 2010. O projeto recebe apoio do Conselho Nacional de Desenvolvimento Científico e Tecnológico (CNPq), tendo sido submetido e aprovado no âmbito do Edital Universal ${ }^{8}$. Busca-se, com essa pesquisa, adensar a massa crítica de informações sobre a influência e, do pensamento de Paulo Freire, com a expectativa de que os resultados possam subsidiar a criação/recriação de políticas e práticas educativas, na perspectiva crítico-emancipadora. $\mathrm{O}$ desenho dessa investigação articula pesquisadores e pós-graduandos, de várias regiões do país, em torno do foco dessa investigação, consolidando uma rede freireana de pesquisadores. A realização de seminários, encontros de pesquisa, têm sido uma valiosa estratégia que vem ganhando força nesse desenho que se faz em colaboração. Esses seminários se constituem em espaços/tempos privilegiados de articulação e formação dos pesquisadores e respondem às necessidades de planejamento e discussão de resultados, configurando-se como uma construção coletiva na qual se põe em prática a dialogicidade freireana.

A metodologia da pesquisa caracteriza-se pela investigação crítica, de abordagem qualitativa. Busca-se apreender a práxis por meio da análise de produções bibliográficas, documentos e, especialmente, de dados empíricos coletados em estudos de campo. Esses estudos têm o objetivo de analisar como o pensamento de Paulo Freire vem se materializando e sendo reinventado em políticas e práticas de projetos/experiências de educação que se propõem a trabalhar com o pensamento de Freire. Compõem a equipe desse projeto, coordenado pela professora Dra. Ana Maria Saul, 28 pesquisadores, sediados em 15

\footnotetext{
${ }^{8}$ Esse projeto foi também aprovado no Edital de Bolsa Produtividade Acadêmica, contemplando a coordenadora da pesquisa, professora Ana Maria Saul.
}

Revista Reflexão e Ação, Santa Cruz do Sul, v. 25, n. 2, p. 119-133, Maio./Ago. 2017.

http://online.unisc.br/seer/index.php/reflex/index 
Instituições de Ensino Superior ${ }^{9}$, localizadas em 11 Estados e 5 consultores, sendo três deles, internacionais ${ }^{10}$.

Os resultados da pesquisa têm demonstrado que a construção da escola pública popular e democrática vem sendo um paradigma inspirador de políticas de educação em vários municípios, em especial, daqueles que se caracterizam como 'administrações populares', e se comprometem com a educação crítico-emancipadora. Constata-se, assim, que o pensamento de Paulo Freire continua vivo e atual, oferecendo contribuições relevantes para políticas e práticas educativas penetrando, também, em diferentes áreas e subáreas do conhecimento, alongando-se em diferentes campos de estudo, ao tempo em que subsidia análises de problemáticas contemporâneas.

\section{CONSIDERAÇÕES FINAIS}

Ao final desse texto é importante remarcar que nessas últimas duas décadas, que marcam a ausência de Paulo Freire, a Cátedra Paulo Freire da PUC-SP convive cada vez mais com a sua presença, por meio de seu legado buscando pesquisar a materialização da pedagogia freireana. Dessa forma, homenageamos Paulo Freire do jeito que ele gostaria de ser homenageado, estudando com rigorosidade o seu pensamento, com posturas críticas, e com a perspectiva de reinventá-lo. Quando falamos em reinvenção, estamos nos referindo à necessidade de aprofundar compreensões de sua obra e de adentrar novos campos de estudos que possam ser a ela relacionados, de modo a ampliar o quadro de análise dos problemas contemporâneos.

Freire segue inspirando, nesse novo milênio, reflexões e práticas que concretizam conceitos/categoria em diferentes contextos da realidade brasileira e internacional e mostram perspectivas promissoras na direção de uma educação com qualidade social. Demonstra-se, no conjunto dos estudos que têm sido realizados e divulgados pelos pesquisadores da Cátedra Paulo Freire que a obra freireana contribui, efetivamente, com um pensamento e uma prática progressistas que têm, no horizonte, a humanização e a utopia de uma sociedade mais democrática, justa e solidária.

\footnotetext{
9 PUC-SP, UFPA, UEPA, UFPE, UECE, UFRN, UFPB, UFES, PUC-M, UFSCar, USP, UNICASTELO, UNISANTOS. UFSC, UNOCHAPECÓ.

${ }^{10}$ São consultores dessa pesquisa os professores Mário Sergio Cortella (PUC-SP), Carlos Rodrigues Brandão (UNICAMP), Michael Apple (Wisconsin University/EUA), Licínio Lima (Universidade do Minho/Pt) e Juan Carlos Tedesco (UNTREF/Argentina).

Revista Reflexão e Ação, Santa Cruz do Sul, v. 25, n. 2, p. 119-133, Maio./Ago. 2017.

http://online.unisc.br/seer/index.php/reflex/index
} 
Volto agora às primeiras palavras desse texto para dizer que nesses 20 anos, Freire "saiu à moda de quem, saindo, fica".

\title{
TEACHING AND RESEARCH AT PUC-SP NOTCH 20 YEARS OF PRESENCE/ ABSENCE OF PAULO FREIRE
}

\begin{abstract}
Paulo Freire was a professor at the Pontifical Catholic University of São Paulo (PUC-SP), for almost two decades, since his return from exile. When he was no longer among us in 1998, the rector of PUC-SP created the Cathedra Paulo Freire, a unique academic space for the development of studies and research on and from Paulo Freire's work. After twenty years of absence of the author of Pedagogy of the Oppressed, it is possible to affirm that his absence is presence in the world, because his thought is classic and timeliness. This article aims to present how freirean pedagogy continues to be studied, researched and reinvented at the Cathedra Paulo Freire of PUC-SP. The emphasis of this text is to demonstrate the possibility of materializing the "teaching-research" relationship, as understood by Paulo Freire, and how, a nationwide research analyzes the legacy and the reinvention of the thought of this author that left us "in a way of whom, leaving, stays".
\end{abstract}

Keywords: Paulo Freire; Teaching-Research; Cathedra Paulo Freire

\section{ENSEÑANZA Y LA INVESTIGACIÓN EN PUC-SP MARCA 20 AÑOS DE PRESENCIA/AUSENCIA DE PAULO FREIRE}

\section{Resumen}

Paulo Freire fue profesor de la Universidad Católica de Sao Paulo (PUC-SP) por un período de casi dos décadas, desde su regreso del exilio. Cuando no estaba más con nosotros, en 1998, la rectoría de la PUC-SP creó la Cátedra Paulo Freire, un espacio académico único para el desarrollo de estudios e investigaciones sobre y desde el trabajo de Paulo Freire. Transcurrido veinte años de ausencia del autor de la Pedagogía del Oprimido, está claro que su ausencia es presencia en el mundo, debido a su forma de pensar que és clásica y actual. Este artículo tiene como objetivo presentar como la pedagogía de Freire aún es estudiada, investigada y Revista Reflexão e Ação, Santa Cruz do Sul, v. 25, n. 2, p. 119-133, Maio./Ago. 2017.

http://online.unisc.br/seer/index.php/reflex/index 
reinventó en la Cátedra Paulo Freire en la PUC-SP. Lo más destacado de este trabajo es demostrar la posibilidad de materializar la relación "enseñanza-investigación", tal como se entendía por Paulo Freire, y como una investigación a nivel nacional analiza el legado y la reinvención del pensamiento de este autor que nos dejó "con estilo de quién, hacia fuera, resta".

Palabras clave: Paulo Freire; Enseñanza-Investigación; Cátedra Paulo Freire

\section{REFERÊNCIAS}

CORTELLA, Mário Sérgio. Paulo Freire: um pensamento clássico e atual. Revista eCurriculum, São Paulo, v.7, n.3, p.1-14, set./dez. 2011. Disponível em:

<http://www.pucsp.br/ecurriculum>. Acesso em: 20 abr. 2012.

FREIRE, Paulo. Ação cultural para a liberdade e outros escritos. Rio de Janeiro: Paz e Terra, 1981.

. A Educação na cidade. São Paulo: Cortez Editora, 1991.

. À sombra dessa mangueira. São Paulo: Editora Olho d'agua, 1995.

. Pedagogia da autonomia: saberes necessários à prática educativa. Rio de Janeiro:

Paz e Terra, 1996.

. Pedagogia do oprimido. Rio de Janeiro: Paz e Terra, 1987.

. Política e educação. São Paulo: Cortez Editora, 1993a.

. Professora sim tia não: cartas a quem ousa ensinar. São Paulo: Paz e Terra, 1993b.

2008.

; SHOR, Ira. Medo e ousadia: o cotidiano do professor. São Paulo: Paz e Terra, [1987]

NÓVOA, António. Paulo Freire (1921-1997): a “inteireza" de um pedagogo utópico. In:

APPLE, M. W.; NÓVOA, A. (Orgs.). Paulo Freire: política e pedagogia. Porto: Porto

Editora, 1998. p. 167-187.

SÃO PAULO (Município). Aos que fazem educação conosco em São Paulo. D.O.M. de São Paulo, São Paulo, SP, v. 34, n. 21, p. 1-11, fev. 1989.

SAUL, Ana Maria. Paulo Freire na atualidade: legado e reinvenção. Revista e-Curriculum, São Paulo, v.14, n.01, p. 09-34, jan./mar. 2016. Disponível em: <http://www.pucsp.br/ecurriculum>. Acesso em: 16 jan. 2017. 
SAUL. A. M.; SAUL, A. Mudar é difícil, mas é possível e urgente: um novo sentido para o projeto político pedagógico da escola. Revista Teias, Rio de Janeiro, v. 14, n. 33, p. 102-120, 2013. Disponível em:

<http://http://www.epublicacoes.uerj.br/index.php/revistateias/article/view/24367>. Acesso em: 16 jan. 2017.

Uma prática docente inspirada na pedagogia freireana: a experiência na Cátedra Paulo Freire da PUC-SP. Revista Interritórios, Caruaru, v. 2, p. 71-84. 2016. Disponível em:

<http://periodicos.ufpe.br/revistas/index.php/interritorios/article/view/5049>. Acesso em: 10 jan. 2017.

SHUGURENSKY, Daniel. Paulo Freire. New York: Bloomsbury, [2011] 2014. 